\title{
Factors associated with measures of sarcopenia in pre and postmenopausal women
}

Nirmala Rathnayake ${ }^{{ }^{*}} \mathbb{D}$, Gayani Alwis², Janaka Lenora ${ }^{3}$ and Sarath Lekamwasam ${ }^{4}$

\begin{abstract}
Background: Menopause associated low serum estradiol marks varieties of derangements in muscle mass and functions leading to sarcopenia. This cross-sectional study was carried out to examine the factors associated with measures of sarcopenia; skeletal muscle mass (SMM), muscle strength and physical performance (PP) in a group of premenopausal (PrMW) and postmenopausal women (PMW) selected from Sri Lanka.
\end{abstract}

Methods: Randomly selected 184 PrMW and 166 PMW from Galle district, Sri Lanka were studied. SMM was measured with duel energy $X$ ray absorptiometry and relative appendicular SMM index (RSMl; $\left.\mathrm{kg} / \mathrm{m}^{2}\right)$ was calculated. Other measurements made include handgrip strength (HGS; kg) and gait speed (GS; m/s), anthropometric indices, consumption of macro and micronutrients, and pattern of physical activities (PA). A serum sample was analyzed for fasting insulin, serum estradiol and vitamin D. Variables which significantly correlated with RSMI, HGS and GS of PrMW and PMW were separately entered into multiple linear regression models to extract the associated factors.

Results: Mean (SD) age of PrMW and PMW were 42.4 (6.0) and 55.8 (3.8) years respectively. In the regression analysis, RSMI in PrMW showed significant associations with body mass index (BMI), HGS, total-body-fat-mass (TBFM) and weight (adjusted $\mathrm{R}^{2}=0.85$ ) and in PMW with BMI, weight, TBFM, hip-circumference and fasting insulin (adjusted $\left.R^{2}=0.80\right)$. BMI showed the strongest association with RSMI in both PrMW $\left(r=0.87, R^{2}=0.76\right)$ and in PMW $(r=0.87$, $\left.R^{2}=0.76\right)$. HGS in PrMW showed significant associations with appendicular SMM (ASMM), total-body-bone-mineralcontent, vigorous PA score, age and weight (adjusted $R^{2}=0.33$ ) and in PMW with ASMM and height (adjusted $\left.R^{2}=0.23\right)$. ASMM showed the strongest association with HGS in both PrMW $\left(r=0.44, R^{2}=0.20\right)$ and PMW $(r=0.44$, $R^{2}=0.20$ ). GS in PrMW showed significant associations with height, $B M l$ and energy consumption (adjusted $R^{2}=0.13$ ) while in PMW, with carbohydrate consumption and total-body-bone-mineral-density (adjusted $R^{2}=0.09$ ). While in PrMW, height showed the strongest association with $G S\left(r=0.28, R^{2}=0.08\right)$ in PMW, it was carbohydrate consumption $\left(r=0.24, R^{2}=0.06\right)$.

Conclusions: Factors that are associated with different measures of sarcopenia are not uniform and vary widely from anthropometry to nutrient intake indicating that these measures are somewhat independent and are governed by different factors.

Keywords: Muscle strength, Physical performance, Postmenopausal women, Premenopausal women, Skeletal muscle mass

\footnotetext{
*Correspondence: nirmala.priyanthi@gmail.com

1 Department of Nursing, Faculty of Allied Health Sciences, University of Ruhuna, Galle, Sri Lanka

Full list of author information is available at the end of the article
}

\section{Background}

Sarcopenia is a syndrome characterized by progressive loss of skeletal muscle mass (SMM) [1] along with loss of muscle strength and physical performance (PP) that 
creates adverse outcomes such as physical disability, poor quality of life (QOL) and death [2-4]. Low serum estrogen in the postmenopausal period is the main cause of the rapid decline in SMM, muscle strength and PP seen in old age [5].

Relative appendicular SMM index (RSMI-height adjusted appendicular SMM) which is the primary measure of SMM together with loss of muscle strength and/or PP is used to categorize sarcopenia [1, 6]. Muscle strength and PP are evaluated by handgrip strength (HGS) and gait speed (GS), respectively [1].

SMM is a key component of body composition accounting for $30-40 \%$ of total body weight and it correlates with physical functions and general health status [7]. SMM in women peaks around the third decade and decreases gradually afterwards before an accelerated decline after the fifth decade [7]. Women begin to lose muscle strength around their fifth and sixth decade of life [7] and experience about $21 \%$ reduction of muscle strength between $25-55$ years [8]. The annual decline in PPs is around $1-2 \%$ after 50 years and reaches $3 \%$ after the age of 60 years [9]. The association observed between muscle strength and circulating estrogen suggests that these changes are partly related to hormonal changes seen around menopause [7]. The poor PP in women compared to men suggest that gender-specific factors across life may influence the maximum PP achieved at the end of linear growth and the rate of decline with age $[10,11]$.

The pathophysiology of sarcopenia is multifaceted and includes many causes. Primary sarcopenia is involved with the age related declining of SMM and muscle function accompanied by lack of sex hormone, apoptosis and mitochondrial dysfunction. Secondary sarcopenia is associated with endocrine, nutrition, disuse and neurodegenerative disorders [1]. Several mechanisms such as protein synthesis, proteolysis, neuromuscular integrity and muscle fat content may be involved in the onset and progression of sarcopenia. In an individual with sarcopenia, several mechanisms may be involved, and relative contributions may vary over time [1].

Indices of sarcopenia such as RSMI, HGS and PP are under the influence of a multitude of factors and substantial overlaps of these factors are seen. While one measure of sarcopenia is linked with many factors, one particular factor can have influence on several indices of sarcopenia. Apart from low estrogen; age, physical disability, physical inactivity, low testosterone, low vitamin D [1218] and increased fat mass [19-21], are linked with low SMM in women. Further, muscle strength and PPs are also associated with vitamin $\mathrm{D}$, other nutrients, serum estradiol, inflammatory conditions and physical inactivity $[7,18,22,23]$.
Understanding the factors leading to low SMM, muscle strength and PP in women is important to optimize their physical functions and reduce disability. Even though factors that determines SMM, muscle strength and PP are the focus of current research, most studies has been carried out mainly in European and high-income countries involving elderly populations. The findings of these studies cannot be directly applied to women outside those countries, particularly those in South Asian countries where genetic and non-genetic factors are different from Western populations. Thus, this study was designed to examine the factors associated with measures of sarcopenia i.e., SMM, muscle strength and PP in premenopausal women (PrMW) and postmenopausal women (PMW), selected from the Southern part of Sri Lanka.

\section{Methods}

Study design, setting and subjects

A community-based cross sectional study was carried out in Galle district, Sri Lanka, from June 2015 to January 2017 [24]. Two groups of apparently healthy communitydwelling PrMW ( $\mathrm{n}=184$, aged $30-55$ years) and PMW $(\mathrm{n}=166$, aged $45-60$ years) selected using multi-stage cluster sampling were included in the study. Menopausal status was determined based on the classification of Stages of Reproductive Aging Workshop (STRAW) [24] wherein the premenopausal status was defined by regular or irregular menstruation occurring naturally (PrMW) while women who have not menstruated within the previous 12 months were considered as PMW. Women who used thyroxin, corticosteroids, insulin, hormone replacement therapy or hormonal contraceptives were excluded from the study. Those who were pregnant or lactating, and on dedicated dietary programs or supervised exercise programs (following a dietary program under the supervision of a dietician or aiming to achieve a weight or a BMI target and following an exercise program under the instruction of physical instructor or aiming to achieve a weight or a BMI target) and those who had a chronic disease (non-communicable diseases, chronic infections, polycystic ovary syndrome or chronic major organ diseases) were also excluded.

\section{Data collection and Measurements}

Central-type DXA scanner (Hologic Discovery W, Hologic Inc, Bedford, MA, USA) was used to measure the SMM (kg) adhering to the manufacturer's protocol. The procedure was carried out by the same technician who calibrated the device on each scanning day. Analytical software provided by the DXA manufacturer was used to analyze SMM. ASMM was calculated by the sum of SMM of all four limbs and the RSMI $\left(\mathrm{kg} / \mathrm{m}^{2}\right)$ was calculated using the following formula [25]; RSMI=ASMM 
in $\mathrm{kg} /$ height in meters ${ }^{2}$. In addition, total body fat mass (TBFM), total body bone mineral density (TBBMD) and total body bone mineral content (TBBMC) were measured using the same DXA scanner.

HGS $(\mathrm{kg})$ of the dominant side was measured [26] using the Lafayette hand held dynamometer (Lafayette Instrument Co, Sagamore Parkway North, USA). During the test, the subjects were asked to hold the dynamometer with the dominant hand on upright position with the arm at right angles and the elbow by the side of the body [26].

Four (4) meter customary paced walking; the time taken to walk the central four meters of an eight meter course at a usual self-selected pace was measured to detect the GS $(\mathrm{m} / \mathrm{s})$. In order to eliminate the effects of acceleration and deceleration, the initial and final two meters were excluded from the calculation.

Both HGS and GS tests were done twice and were observed by a single trained investigator (the principal investigator of the study). Average of two measurements was used for the analyses [26].

Body weight $(\mathrm{kg})$ and height $(\mathrm{m})$ were measured to the nearest $0.1 \mathrm{~kg}$ and $0.1 \mathrm{~cm}$ respectively with a calibrated Stadiometer (NAGATA, Tainan, Taiwan). Circumferences $(\mathrm{cm})$ of waist (WC) and hip (HC) were measured to the nearest $0.1 \mathrm{~cm}$ with a plastic measuring tape. Body mass index (BMI, $\mathrm{kg} / \mathrm{m}^{2}$ ) and waist to hip ratio (WHR) were calculated. All anthropometric indices were measured according to the standard protocol [27] by the same investigator who observed the HGS and GS to ensure the consistency of measurements following standard guidelines.

The pattern of physical activity (PA) was determined with the short version of the international PA questionnaire (IPAQ) [28]. Daily total energy, carbohydrate, protein, fats and calcium consumption were obtained from a $24 \mathrm{~h}$ dietary recall (HDR) method. The subjects were asked to recall all foods and beverages, consumed over the previous 24-h period. Respondents were probed for the types of foods and food preparation methods. For uncommon mixed meals, the details of recipes and preparation methods were collected at the time of taking the 24 HDR. All foods recorded in 24 HDR were converted into grams and then, the intake of total energy were analyzed using Indian food composition tables [29] and Sri Lankan food composition tables [30].

A sample of venous blood $(4 \mathrm{~mL}$ ) was drawn from the antecubital vein in the non-dominant side in the morning after the subject had fasted for 10-12 h. Fasting insulin, serum estradiol and vitamin D (25-hydroxyvitamin D $(25(\mathrm{OH}) \mathrm{D})$ levels were measured with Enzyme Linked Immuno Sorbent Assay (ELISA) technique. All the investigations were performed in duplicate tests at the standard laboratory premises of the Nuclear Medicine Unit, Faculty of Medicine, University of Ruhuna under expert scientific involvement.

\section{Statistical analyses}

Descriptive statistics; means (SD) or frequency (\%), were used to describe the data. Differences between PrMW and PMW were compared using independent sample $t$ test. Correlation between variables and the RSMI, HGS and GS were evaluated with Pearson correlation (r). The variables which showed significant correlations were entered into a multiple regression model in both "enter" and "stepwise" manner to detect significant factors associated with RSMI, HGS and GS. Correlations and regression analyses were done for PrMW and PMW, seperately. The collinearity between variables were verified by the variance inflation factor (VIF) and tolerance (T) values. Thus, VIF values $<10$ and $\mathrm{T}$ values above 0.1 were considered as acceptable. Data were analysed using SPSS 20.0 and $p$ value $<0.05$ was considered statistically significant.

\section{Ethical consideration}

Ethical clearance for this study was obtained from the Ethical Review Committee, Faculty of Medicine, University of Ruhuna, Sri Lanka (Reference number; 24.09.2014:3.2). Written informed consent was obtained from each subject before participation.

\section{Results}

\section{Basic characteristics of PrMW and PMW}

Sociodemographic characteristics of the PrMW and PMW who participated in the study were published in our previous work [24]. Mean (SD) age of PrMW and PMW were 42.4 (6.0) and 55.8 (3.8) years respectively. The basic characteristics of study subjects are shown in Table 1. Three main measures of sarcopenia; RSMI, HGS and GS were higher in PrMW compared to PMW $(\mathrm{p}<0.01)$. Variables correlated with RSMI, HGS and PP of PrMW and PMW are shown in Tables 2, 3 and 4 respectively.

\section{Factors associated with RSMI, HGS and GS in PrMW and PMW}

BMI, HGS, TBFM and weight showed significant associations with RSMI in PrMW $\left(\mathrm{R}=0.92, \mathrm{R}^{2}=0.85\right)$ while BMI, weight, TBFM, $\mathrm{HC}$ and fasting insulin were associated with RSMI among PMW $\left(R=0.90, R^{2}=0.80\right)$ (Table 5). Among all, BMI showed the strongest association with RSMI in both PrMW $\left(r=0.87, \mathrm{R}^{2}=0.76\right)$ and PMW $\left(r=0.87, R^{2}=0.76\right)$.

ASMM, TBBMC, vigorous PA score, age and weight showed significant associations with HGS in PrMW 
Table 1 Basic characteristics of PrMW and PMW

\begin{tabular}{|c|c|c|c|}
\hline Characteristics & $\begin{array}{l}\text { PrMW }(n=184) \\
\text { Mean }(S D)\end{array}$ & $\begin{array}{l}\text { PMW }(n=166) \\
\text { Mean (SD) }\end{array}$ & $p$ value * \\
\hline \multicolumn{4}{|l|}{ Measures of sarcopenia } \\
\hline $\operatorname{RSMI}\left(\mathrm{kg} / \mathrm{m}^{2}\right)$ & $6.9(0.9)$ & $6.6(1.0)$ & 0.008 \\
\hline HGS (kg) & $19.0(6.0)$ & $15.2(4.8)$ & $<0.001$ \\
\hline $\mathrm{GS}(\mathrm{m} / \mathrm{s})$ & $1.2(0.1)$ & $1.0(0.16)$ & $<0.001$ \\
\hline \multicolumn{4}{|l|}{ Anthropometry indices } \\
\hline Weight (kg) & $58.0(9.8)$ & $57.0(11.9)$ & 0.44 \\
\hline Height (m) & $1.5(0.1)$ & $1.4(0.1)$ & $<0.001$ \\
\hline WC (cm) & $82.5(9.8)$ & $83.3(12.3)$ & 0.50 \\
\hline $\mathrm{HC}(\mathrm{cm})$ & $97.0(8.5)$ & $98.7(10.1)$ & 0.09 \\
\hline WHR & $0.8(0.1)$ & $0.8(0.1)$ & 0.47 \\
\hline $\mathrm{BMI}\left(\mathrm{kg} / \mathrm{m}^{2}\right)$ & $24.9(4.0)$ & $25.9(4.5)$ & 0.37 \\
\hline \multicolumn{4}{|l|}{ Body composition indices } \\
\hline TBBMD $\left(\mathrm{g} / \mathrm{cm}^{2}\right)$ & $0.892(0.060)$ & $0.812(0.081)$ & $<0.001$ \\
\hline TBBMC (g) & $1283.6(183.1)$ & $1092.8(250.2)$ & $<0.001$ \\
\hline TBFM (kg) & $18.4(5.6)$ & $19.6(6.4)$ & 0.30 \\
\hline ASMM (kg) & $16.0(2.5)$ & $14.8(2.9)$ & $<0.001$ \\
\hline \multicolumn{4}{|l|}{ Serum markers } \\
\hline Vitamin25(OH)D (n/mol) & $18.7(2.1)$ & $18.5(2.7)$ & 0.34 \\
\hline Estradiol (m/U/L) & $149.5(107.6)$ & $57.3(55.4)$ & $<0.001$ \\
\hline Fasting insulin (g/dl) & $9.9(5.1)$ & $11.1(6.6)$ & 0.05 \\
\hline \multicolumn{4}{|l|}{ Lifestyle factors } \\
\hline \multicolumn{4}{|l|}{ Physical activity pattern } \\
\hline Walking PA score (MET/min/week) & $829.2(186.7)$ & $580.2(156.8)$ & 0.01 \\
\hline Moderate PA score (MET/min/week) & $4868.0(574.2)$ & $4770.12(857.0)$ & 0.20 \\
\hline Vigorous PA score (MET/min/week) & $1785.2(1784.9)$ & $2297.59(1917.4)$ & 0.01 \\
\hline Total PA score (MET/min/week) & $7482.5(2400.0)$ & $7648.03(2534.6)$ & 0.53 \\
\hline \multicolumn{4}{|l|}{ Macro and micro nutrients consumption } \\
\hline Total energy (kcal) & $1368.2(412.5)$ & $1154.1(331.8)$ & $<0.001$ \\
\hline Protein $(\mathrm{g})$ & $38.7(13.4)$ & $32.2(12.1)$ & $<0.001$ \\
\hline Fat (g) & $30.1(19.0)$ & $28.1(19.6)$ & 0.34 \\
\hline Carbohydrates (g) & $236.0(79.2)$ & $195.1(68.9)$ & $<0.001$ \\
\hline Calcium (mg) & $293.8(180.4)$ & $288.0(245.3)$ & 0.79 \\
\hline
\end{tabular}

PrMW premenopausal women, $P M W$ postmenopausal women, $W C$ waist circumference, $H C$ hip circumference, WHR waist to hip ratio, $B M I$ body mass index, $A S M M$ appendicular skeletal muscle mass, $R S M I$ relative ASMM, HGS hand grip strength, GS gait speed, TBBMD total body bone mineral density, TBBMC total body bone mineral content, TBFM total body fat mass, PA physical activities

${ }^{*} p$ values derived from independent sample $t$ test

( $\left.R=0.58, R^{2}=0.33\right)$ while ASMM and height showed significant associations with HGS in PMW $(R=0.48$, $\mathrm{R}^{2}=0.23$ ) (Table 6). ASMM showed the strongest association with HGS in both PrMW $\left(r=0.44, \mathrm{R}^{2}=0.19\right)$ and PMW ( $\left.r=0.44, R^{2}=0.19\right)$.

GS in PrMW showed significant associations with height, BMI and energy consumption $(\mathrm{R}=0.37$, $\left.\mathrm{R}^{2}=0.13\right)$ while in PMW, carbohydrate consumption and TBBMD showed significant associations with GS $\left(\mathrm{R}=0.30, \mathrm{R}^{2}=0.09\right)$ (Table 7$)$. The strongest factor associated with GS in PrMW was height $\left(r=0.28, R^{2}=0.08\right)$ while in PMW, it was carbohydrate consumption $\left(\mathrm{r}=0.24, \mathrm{R}^{2}=0.06\right)$.

\section{Discussion}

This study revealed that a diversity of factors including measures of anthropometry, body composition and lifestyle, is associated with the three main measures of sarcopenia in PrMW and PMW. Though studies on factors associated with muscle mass in women are common, studies focusing on all three measures of sarcopenia in a single study are scarce. 
Table 2 Variables correlated (Pearson's correlations) with RSMI in PrMW and PMW

\begin{tabular}{|c|c|c|c|}
\hline \multicolumn{2}{|l|}{ PrMW $(n=184)$} & \multicolumn{2}{|l|}{ PMW $(n=166)$} \\
\hline Correlated variables & Correlation ( $r$ ) & Correlated variables & Correlation ( $r$ ) \\
\hline Weight & $0.83^{* *}$ & Weight & $0.84^{* *}$ \\
\hline WC & $0.80^{* *}$ & WC & $0.79^{* *}$ \\
\hline $\mathrm{HC}$ & $0.77^{* *}$ & $\mathrm{HC}$ & $0.79^{* *}$ \\
\hline BMI & $0.87^{* *}$ & BMI & $0.87^{* *}$ \\
\hline WHR & $0.47^{* *}$ & WHR & $0.26^{* *}$ \\
\hline TBFM & $0.74^{* *}$ & TBFM & $0.70^{* *}$ \\
\hline TBBMD & $0.32^{* *}$ & TBBMD & $0.46^{* *}$ \\
\hline TBBMC & $0.40^{* *}$ & TBBMC & $0.55^{* *}$ \\
\hline HGS & $0.27^{* *}$ & HGS & $0.33^{* *}$ \\
\hline Fasting insulin & $-0.39^{* *}$ & Fasting insulin & $-0.37^{* *}$ \\
\hline- & - & Vitamin 25(OH)D & $0.20^{* *}$ \\
\hline- & - & Walking PA & $0.16^{*}$ \\
\hline
\end{tabular}

PrMW premenopausal women, PMW postmenopausal women, WC waist circumference, $H C$ hip circumference, WHR waist to hip ratio, $B M I$ body mass index, $A S M M$ appendicular skeletal muscle mass, $R S M I$ relative $A S M M, H G S$ hand grip strength, GS gait speed, $T B B M D$ total body bone mineral density, TBBMC total body bone mineral content, TBFM total body fat mass, PA physical activities

**Correlation is significant at the 0.01 level (2-tailed)

${ }^{*}$ Correlation is significant at the 0.05 level (2-tailed)

Table 3 Variables correlated (Pearson's correlations) with HGS in PrMW and PMW

\begin{tabular}{llll}
\hline PrMW $(\mathbf{n}=\mathbf{1 8 4})$ & & PMW $(\mathbf{n}=166)$ & Correlation $(\mathbf{r})$ \\
\cline { 4 - 4 } Correlated variables & Correlation $(\mathbf{r})$ & Correlated variables & $0.40^{* *}$ \\
\hline Age & $-0.20^{* *}$ & Weight & $0.40^{* *}$ \\
Weight & $0.26^{* *}$ & Height & $0.28^{* *}$ \\
Height & $0.41^{* *}$ & WC & $0.33^{* *}$ \\
WC & $0.19^{* *}$ & HC & $0.27^{* *}$ \\
HC & $0.16^{*}$ & BMl & $0.35^{* *}$ \\
WHR & $0.15^{*}$ & TBFM & $0.37^{* *}$ \\
TBBMD & $0.32^{* *}$ & TBBMD & $0.43^{* *}$ \\
TBBMC & $0.42^{* *}$ & TBBMC & $0.44^{* *}$ \\
ASMM & $0.44^{* *}$ & ASMM & $0.16^{*}$ \\
GS & $0.22^{* *}$ & Serum Estradiol & $0.17^{*}$ \\
Fasting insulin & $-0.10^{*}$ & Energy consumption & $0.19^{*}$ \\
Energy consumption & $0.17^{*}$ & Protein consumption & - \\
Carbohydrate consumption & $0.15^{*}$ & - & - \\
Vigorous PA & $0.20^{*}$ & - & \\
\hline
\end{tabular}

PrMW premenopausal women, $P M W$ postmenopausal women, $W C$ waist circumference, $H C$ hip circumference, $W H R$ waist to hip ratio, $B M I$ body mass index, $A S M M$ appendicular skeletal muscle mass, RSMI relative ASMM, HGS hand grip strength, GS gait speed, TBBMD total body bone mineral density, TBBMC total body bone mineral content, TBFM total body fat mass, $P A$ physical activities

** Correlation is significant at the 0.01 level (2-tailed)

${ }^{*}$ Correlation is significant at the 0.05 level (2-tailed)

Similar to our findings, previous studies have shown that anthropometric indices [14, 20,31,32] and TBFM [19] are closely associated with SMM in women. Similarly, Maltais et al. [7] have shown fasting insulin to be associated with SMM in PMW. SMM is the major metabolically active body compartment for the disposal of glucose in healthy individuals [33]; therefore, the loss of SMM can disrupt this mechanism resulting in hyperinsulinemia. Even though previous studies have reported SMM in women to be associated with low 
Table 4 Variables correlated (Pearson's correlations) with GS in PrMW and PMW

\begin{tabular}{|c|c|c|c|}
\hline \multicolumn{2}{|l|}{ PrMW (n=184) } & \multicolumn{2}{|l|}{ PMW $(n=166)$} \\
\hline Correlated variables & Correlation (r) & Correlated variables & Correlation ( $r$ ) \\
\hline Height & $0.28^{* *}$ & TBBMD & $0.18^{*}$ \\
\hline $\mathrm{BMI}$ & $-0.20^{* *}$ & TBBMC & $0.17^{*}$ \\
\hline HGS & $0.22^{* *}$ & Energy consumption & $0.24^{* *}$ \\
\hline Energy consumption & $0.18^{*}$ & Carbohydrate consumption & $0.24^{* *}$ \\
\hline Carbohydrate consumption & $0.16^{*}$ & - & - \\
\hline
\end{tabular}

PrMW premenopausal women, $P M W$ postmenopausal women, BMI body mass index, HGS hand grip strength, TBBMD total body bone mineral density, TBBMC total body bone mineral content

** Correlation is significant at the 0.01 level (2-tailed)

*Correlation is significant at the 0.05 level (2-tailed)

Table 5 Factors associated with RSMI of PrMW and PMW in multiple regression analysis

\begin{tabular}{|c|c|c|c|c|c|}
\hline \multirow[t]{2}{*}{ Factors } & \multicolumn{2}{|c|}{$\begin{array}{l}\text { Unstandardized } \\
\text { coefficients }\end{array}$} & \multirow{2}{*}{$\begin{array}{l}\text { Standardized } \\
\text { coefficients } \\
\beta\end{array}$} & \multirow[t]{2}{*}{$\mathbf{t}$} & \multirow[t]{2}{*}{ Sig } \\
\hline & B & SE & & & \\
\hline \multicolumn{6}{|l|}{$\operatorname{PrMW}(\mathrm{n}=184)$} \\
\hline $\mathrm{BMI}$ & 0.24 & 0.01 & 1.04 & 13.49 & $<0.001$ \\
\hline $\mathrm{HGS}$ & 0.01 & 0.005 & 0.10 & 3.30 & 0.001 \\
\hline TBFM & 0.12 & 0.01 & 0.74 & 8.54 & $<0.001$ \\
\hline Weight & 0.05 & 0.008 & 0.55 & 6.47 & $<0.001$ \\
\hline \multicolumn{6}{|c|}{$\begin{array}{l}\text { Overall model } R=0.92 \text {, Adjusted } R^{2}=0.85, \mathrm{SEE}=0.36 \text {, Durbin-Wat- } \\
\text { son }=1.81 \text { ANOVA; } F=267.24, p<0.001\end{array}$} \\
\hline \multicolumn{6}{|c|}{ PMW $(n=166)$} \\
\hline $\mathrm{BMI}$ & 0.18 & 0.02 & 0.76 & 8.05 & $<0.001$ \\
\hline Weight & 0.05 & 0.01 & 0.60 & 5.33 & $<0.001$ \\
\hline TBFM & 0.05 & 0.01 & 0.30 & 3.84 & $<0.001$ \\
\hline $\mathrm{HC}$ & 0.02 & 0.01 & 0.22 & 3.28 & 0.04 \\
\hline Fasting insulin & 0.01 & 0.006 & 0.07 & 2.05 & 0.04 \\
\hline \multicolumn{6}{|c|}{$\begin{array}{l}\text { Overall model } R=0.90, \text { Adjusted } R^{2}=0.80, S E E=0.47 \text {, Durbin-Wat- } \\
\text { son }=1.80 \text { ANOVA; } F=137.79, p<0.001\end{array}$} \\
\hline
\end{tabular}

PA [19, 34, 35], low protein intake [36-39] and hypovitaminosis D [7, 17, 18, 40], these factors showed only minor correlations with RSMI in the current study. The step-wise regression model excluded them as weak associations. These inconsistencies may be due to the differences in the selection of subjects and the way measurements were taken. Furthermore, the differences could be due to the variations in lifestyle including diet, degree of PA, and economy between communities.

Concordant with our observations, HGS has been shown to be associated with ASMM [41-43] in women. Although there is no linear relationship between muscle mass and muscle function, ASMM is a strong predictor of HGS. Da Camara et al. found women with higher
Table 6 Factors associated with HGS of PrMW and PMW in Multiple Regression Analysis

\begin{tabular}{|c|c|c|c|c|c|}
\hline \multirow[t]{2}{*}{ Factors } & \multicolumn{2}{|c|}{$\begin{array}{l}\text { Unstandardized } \\
\text { Coefficients }\end{array}$} & \multirow{2}{*}{$\begin{array}{l}\text { Standardized } \\
\text { Coefficients } \\
\beta\end{array}$} & \multirow[t]{2}{*}{$\mathbf{t}$} & \multirow[t]{2}{*}{ Sig } \\
\hline & B & SE & & & \\
\hline \multicolumn{6}{|l|}{$\operatorname{PrMW}(\mathrm{n}=184)$} \\
\hline TBBMC & 0.11 & 0.003 & 0.31 & 3.85 & $<0.001$ \\
\hline Age & -0.19 & 0.06 & -0.19 & -3.21 & 0.002 \\
\hline Vigorous PA & 0.00 & 0.00 & 0.12 & 1.97 & 0.04 \\
\hline ASMM & 1.37 & 0.34 & 0.57 & 4.04 & $<0.001$ \\
\hline Weight & 0.26 & 0.08 & 0.42 & 3.19 & 0.002 \\
\hline \multicolumn{6}{|c|}{$\begin{array}{l}\text { Overall model } R=0.58 \text {, Adjusted } R^{2}=0.33, \mathrm{SEE}=5.06 \text {, Durbin-Wat- } \\
\text { son }=1.76 \text { ANOVA; } F=18.02, p<0.001\end{array}$} \\
\hline \multicolumn{6}{|c|}{$\operatorname{PMW}(n=166)$} \\
\hline ASMM & 0.53 & 0.14 & 0.31 & 3.80 & $<0.001$ \\
\hline Height & 17.17 & 6.41 & 0.24 & 2.67 & 0.008 \\
\hline \multicolumn{6}{|c|}{$\begin{array}{l}\text { Overall model } R=0.48 \text {, Adjusted } R^{2}=0.23, \mathrm{SEE}=4.28 \text {, Durbin-Wat- } \\
\text { son }=1.90 \text { ANOVA; } F=24.86, p<0.001\end{array}$} \\
\hline
\end{tabular}

PrMW premenopausal women, $P M W$ postmenopausal women, $A S M M$ appendicular skeletal muscle mass, TBBMC total body bone mineral content, $P A$ physical activities

BMI to have higher HGS [44] and this is similar to the association we found between HGS and height and weight. This could be due to the fact that women with higher BMI could possess higher SMM; hence likely to have greater HGS. Keeping with our observation, low PA is linked with low HGS $[2,45,46]$ in women. It is possible that PA enhance muscle strength by stimulating myofibrillar muscle protein synthesis and inhibiting muscle protein breakdown [47]. Though we found a significant association between bone mineral content (BMC) and HGS in PrMW, previous studies showing such association is scarce. A significant association between osteoporosis and muscle strength, however, has been observed [48] in PMW, previously. This could be due to the fact that the risk factors of osteoporosis 
Table 7 Factors associated with GS of PrMW and PMW in Multiple Regression Analysis

\begin{tabular}{|c|c|c|c|c|c|}
\hline \multirow[t]{2}{*}{ Factors } & \multicolumn{2}{|c|}{ Unstandardized Coefficients } & \multirow{2}{*}{$\begin{array}{l}\text { Standardized Coefficients } \\
\beta\end{array}$} & \multirow[t]{2}{*}{$\mathbf{t}$} & \multirow[t]{2}{*}{ Sig } \\
\hline & B & SE & & & \\
\hline \multicolumn{6}{|l|}{$\operatorname{PrMW}(n=184)$} \\
\hline Height & 0.75 & 0.21 & 0.25 & 3.58 & $<0.001$ \\
\hline BMl & -0.008 & 0.003 & -0.17 & -2.53 & 0.01 \\
\hline Energy consumption & 6.41 & $<0.001$ & 0.15 & 2.18 & 0.03 \\
\hline \multicolumn{6}{|c|}{ Overall model $R=0.37$, Adjusted $R^{2}=0.13, \mathrm{SEE}=0.16$, Durbin-Watson $=1.68$ ANOVA; $F=9.50, p<0.001$} \\
\hline \multicolumn{6}{|l|}{$\operatorname{PMW}(n=166)$} \\
\hline Carbohydrate consumption & 0.001 & 0.00 & 0.24 & 3.26 & 0.001 \\
\hline TBBMD & 0.35 & 0.14 & 0.17 & 2.34 & 0.02 \\
\hline \multicolumn{6}{|c|}{ Overall model $R=0.30$, Adjusted $R^{2}=0.09, \mathrm{SEE}=0.15$, Durbin-Watson $=1.60$ ANOVA; $F=8.52, p<0.001$} \\
\hline
\end{tabular}

PrMW premenopausal women, PMW postmenopausal women, $B M I$ body mass index, TBBMD total body bone mineral density

and sarcopenia, including age, genetics, endocrine function, and mechanical factors are similar [49-51].

Keeping in line with our observations, GS has shown significant associations with low height [52], higher BMI [53] and low bone mineral density (BMD) [54]. The associations seen between GS and height and BMI are understandable. The gait step length is possibly influenced by height while subjects with higher BMI may have poor mobility and lower GS. Association between BMD and GS is understandable as higher GS would mean higher PA and in turn, higher bone density and mineral content [55]. Though our study observed both energy and carbohydrate consumption are linked with GS in both PrMW and PMW, we were unable to find previous studies supporting these associations.

The positive associations seen between measures of sarcopenia and nutritional factors, anthropometric indices, and body composition indices have the potential to be utilized in future health promotion activities. Women in Sri Lanka tend to neglect their nutritional requirements amidst many family responsibilities. They also tend to change from non-vegetarian to vegetarian diet due to religious influences especially in the postmenopausal period. Young women are likely to have a sedentary lifestyle which could lead to loss of SMM, functional limitations and derangements of BMD and BMC. Therefore, health education programs need to focus on food patterns of young women to maintain optimal SMM and its functions. Further, a physically active lifestyle should be promoted among both young and old women focusing on aerobics, strength and balance training activities.

Apart from health promotion at the community level, this information would help clinicians in patient care. Although sarcopenia is not the primary reason to seek medical care, it may co-exist in patients presenting with emphysema, heart failure, falls, fractures, frailty and diabetes. Furthermore, acute sarcopenia may exacerbate these conditions and influence the clinical outcome. Clinicians need to be aware of this possibility and the improvement of muscle mass and functions should be an integral part of the management of such patients. Further, the variation of factors that is associated with the components of sarcopenia between PrMW and PMW need to be clarified.

The current study is a cross-sectional study involving a single geographical area, which limits the generalizability of findings. However, we evaluated many factors that are interconnected with the measures of sarcopenia and this is the first detailed investigation on factors linked with sarcopenic measures among Sri Lankan women. Therefore the findings would lay the foundation for future research.

\section{Conclusions}

We found that many factors are associated with the measures of sarcopenia. BMI was the most significant factor associated with RSMI while ASMM was the most significant factor for HGS of both PrMW and PMW. GS was mostly associated with height and carbohydrate consumption in PrMW and PMW, respectively. The findings suggest that the factors associated with the measures of sarcopenia are not uniform and vary widely from simple body measurements such as anthropometry to nutrient intake irrespective of menopausal status. It emphasizes that these measures of sarcopenia are somewhat independent and are governed by different factors.

\section{Abbreviations}

SMM: Skeletal muscle mass; PP: Physical performance; PrMW: Premenopausal women; PMW: Postmenopausal women; DXA: Dual energy x ray absorptiometry.; RSMI: Relative appendicular skeletal muscle mass index.; ASMM: Appendicular skeletal muscle mass.; HGS: Hand grip strength.; GS: Gait speed.; PA: Physical activities.; SD: Standard deviation.; BMI: Body mass index.; TBFM: Total 
body fat mass.; TBMBC: Total body bone mineral content.; TBBMD: Total body bone mineral density.; QOL: Quality of life.; WC: Waist circumference.; HC: Hipcircumference.; WHR: Waist to hip ratio.; IPAQ: International PA questionnaire.; HDR: 24 H dietary recall.; ELISA: Enzyme Linked Immuno Sorbent Assay;iVIF: Variance inflation factor;; T: Tolerance.; STRAW: Stages of Reproductive Aging Workshop.; BMD: Bone mineral density.; BMC: Bone mineral content.

\section{Acknowledgements}

Authors wish to acknowledge Mr. P.B. Aththnayake and Mr. L.A.S. Dharmapriya, technical staff of Nuclear Medicine Unit, Faculty of Medicine, University of Ruhuna, Sri Lanka for their technical support on performing investigations. Further, Ms. M. Kariyawasam and Ms. R. Niroshini, technicians of DXA unit, Teaching Hospital, Karapitiya, Sri Lanka are acknowledged for performing and analyzing the body compositions with DXA.

\section{Authors' contributions}

All authors involved in conception of the study and design of the work, NR involved in data collection, data analysis and initial drafting of the manuscript, GA and JL involved in interpretation of analyzed data, critically reviewing of the manuscript. SL contributed to interpretation of analyzed data and critically reviewing the manuscript for important intellectual content. All authors read and approved the final manuscript.

\section{Funding}

Faculty Research Grant (2014-2015), Faculty of Medicine, University of Ruhuna, Sri Lanka and National Research Council (NRC 15-023), Sri Lanka, funds mainly involved with the collection of data.

\section{Availability of data and materials}

The datasets used and/or analyzed during the current study are available from the corresponding author on reasonable request.

\section{Ethics approval and consent to participate}

Ethical clearance for the study was obtained from the ethical review committee, Faculty of Medicine, University of Ruhuna, Sri Lanka. Informed written consent was obtained from each participant prior to the commencement of the study.

\section{Consent for publication}

Not applicable.

\section{Competing interests}

The authors declare that they have no competing interests.

\section{Author details}

${ }^{1}$ Department of Nursing, Faculty of Allied Health Sciences, University of Ruhuna, Galle, Sri Lanka. ${ }^{2}$ Department of Anatomy, Faculty of Medicine, University of Ruhuna, Galle, Sri Lanka. ${ }^{3}$ Department of Physiology, Faculty of Medicine, University of Ruhuna, Galle, Sri Lanka. ${ }^{4}$ Population Health Research Centre, Department of Medicine, Faculty of Medicine, University of Ruhuna, Galle, Sri Lanka.

Received: 6 July 2020 Accepted: 16 December 2020 Published online: 02 January 2021

\section{References}

1. Cruz-Jentoft AJ, Baeyens JP, Bauer JM, Boirie Y, Cederholm T, Landi F, Martin FC, Michel J-P, Rolland Y, Schneider SM. Sarcopenia: European consensus on definition and diagnosis Report of the European Working Group on Sarcopenia in Older People. Age Ageing. 2010;39:412-23.

2. Lu Y, Niti M, Yap KB, Tan CT, Nyunt MS, Feng L, Tan BY, Chan G, Khoo SA, Chan SM, Yap P. Assessment of sarcopenia among community-dwelling at-risk frail adults aged 65 years and older who received multidomain lifestyle interventions: a secondary analysis of a randomized clinical trial. JAMA Netw Open. 2019;2(10):e1913346.

3. Goodpaster BH, Park SW, Harris TB, Kritchevsky SB, Nevitt M, Schwartz AV, Simonsick EM, Tylavsky FA, Visser M, Newman AB. The loss of skeletal muscle strength, mass, and quality in older adults: the health, aging and body composition study. J Gerontol Ser A Biol Sci Med Sci. 2006;61:1059-64.
4. Delmonico MJ, Harris TB, Lee JS, Visser M, Nevitt M, Kritchevsky SB, Tylavsky FA, Newman AB. Alternative definitions of sarcopenia, lower extremity performance, and functional impairment with aging in older men and women. J Am Geriatr Soc. 2007;55:769-74.

5. Sakuma K, Yamaguchi A. Sarcopenia and age-related endocrine function. Int J Endocrinol. 2012. https://doi.org/10.1155/2012/127362.

6. Cruz-Jentoft AJ, Bahat G, Bauer J, Boirie Y, Bruyère O, Cederholm T, Cooper C, Landi F, Rolland Y, Sayer AA. Sarcopenia: revised European consensus on definition and diagnosis. Age Ageing. 2019;48:16-31.

7. Maltais M, Desroches J, Dionne I. Changes in muscle mass and strength after menopause. J Musculoskelet Neuronal Interact. 2009;9:186-97.

8. Milanović Z, Pantelić S, Trajković N, Sporiš G, Kostić R, James N. Agerelated decrease in physical activity and functional fitness among elderly men and women. Clin Interv Aging. 2013;8:549.

9. Keller K, Engelhardt M. Strength and muscle mass loss with aging process. Age and strength loss. Muscles Ligaments Tendons J. 2013;3:346.

10. Kuh D, Bassey EJ, Butterworth S, Hardy R, Wadsworth ME. Grip strength, postural control, and functional leg power in a representative cohort of British men and women: associations with physical activity, health status, and socioeconomic conditions. J Gerontol Ser A Biol Sci Med Sci. 2005;60:224-31.

11. Rolland YM, Perry lii HM, Patrick P, Banks WA, Morley JE. Loss of appendicular muscle mass and loss of muscle strength in young postmenopausal women. J Gerontol Ser A Biol Sci Med Sci. 2007;62(3):330-5.

12. Fielding RA, Vellas $B$, Evans WJ, Bhasin $S$, Morley JE, Newman AB, van Kan GA, Andrieu S, Bauer J, Breuille D, Cederholm T. Sarcopenia: an undiagnosed condition in older adults. Current consensus definition: prevalence, etiology, and consequences. International working group on sarcopenia. J Am Med Dir Assoc. 2011;12(4):249-56.

13. Kwon I, Shin CH, Kim JH. Associations between skeletal muscle mass, grip strength, and physical and cognitive functions in elderly women: effect of exercise with resistive Theraband. J Exerc Nutr Biochem. 2019;23(3):50.14.

14. Pongchaiyakul C, Limpawattana P, Kotruchin P, Rajatanavin R. Prevalence of sarcopenia and associated factors among Thai population. J Bone Miner Metab. 2013;31:346-50.

15. Tyrovolas S, Koyanagi A, Olaya B, Ayuso-Mateos JL, Miret M, Chatterji S, Tobiasz-Adamczyk B, Koskinen S, Leonardi M, Haro JM. Factors associated with skeletal muscle mass, sarcopenia, and sarcopenic obesity in older adults: a multi-continent study. J Cachexia Sarcopenia Muscle. 2016;7(3):312-21.

16. Tey SL, Chew ST, How CH, Yalawar M, Baggs G, Chow WL, Cheong M, San Ong RH, Husain FS, Kwan SC, Tan CY. Factors associated with muscle mass in community-dwelling older people in Singapore: Findings from the SHIELD study. PLOS ONE. 2019;14(10):e0223222.

17. Marantes I, Achenbach SJ, Atkinson EJ, Khosla S, Melton LJ III, Amin S. Is vitamin $\mathrm{D}$ a determinant of muscle mass and strength? J Bone Miner Res. 2011;26(12):2860-71.

18. Beaudart C, Buckinx F, Rabenda V, Gillain S, Cavalier E, Slomian J, Petermans $J$, Reginster $J$-Y, Bruyère $O$. The effects of vitamin $D$ on skeletal muscle strength, muscle mass, and muscle power: a systematic review and meta-analysis of randomized controlled trials. J Clin Endocrinol Metab. 2014;99:4336-45.

19. Limpawattana P, Assantachai P, Krairit O, Kengkijkosol T, Wittayakom W, Pimporm J, Theeranut A. The predictors of skeletal muscle mass among young Thai adults: a study in the rural area of Thailand. Biomed Res. 2016;27:29-33.

20. Gao L, Jiang J, Yang M, Hao Q, Luo L, Dong B. Prevalence of sarcopenia and associated factors in Chinese community-dwelling elderly: comparison between rural and urban areas. J Am Med Dir Assoc. 2015;16(11):1003-e1.

21. Bunout D, de La Maza MP, Barrera G, Leiva L, Hirsch S. Association between sarcopenia and mortality in healthy older people. Australas J Ageing. 2011;30(2):89-92.

22. Houston DK, Leng X, Bray GA, Hergenroeder AL, Hill JO, Jakicic JM, Johnson KC, Neiberg RH, Marsh AP, Rejeski WJ. A long-term intensive lifestyle intervention and physical function: the look AHEAD Movement and Memory Study. Obesity. 2015;23:77-84.

23. Trombetti A, Reid K, Hars M, Herrmann F, Pasha E, Phillips E, Fielding R. Age-associated declines in muscle mass, strength, power, and physical performance: impact on fear of falling and quality of life. Osteoporos Int. 2016;27:463-71. 
24. Rathnayake N, Lenora J, Alwis G, Lekamwasam S. Prevalence and severity of menopausal symptoms and the quality of life in middle-aged women: a study from Sri Lanka. Nurs Res Pract. 2019;2019:55. https://doi. org/10.1155/2019/2081507.

25. Baumgartner RN, Koehler KM, Gallagher D, Romero L, Heymsfield SB, Ross RR, Garry PJ, Lindeman RD. Epidemiology of sarcopenia among the elderly in New Mexico. Am J Epidemiol. 1998;147:755-63.

26. Lauretani F, Russo CR, Bandinelli S, Bartali B, Cavazzini C, Di lorio A, Corsi AM, Rantanen T, Guralnik JM, Ferrucci L. Age-associated changes in skeletal muscles and their effect on mobility: an operational diagnosis of sarcopenia. J Appl Physiol (1985). 2003;95:1851-60.

27. Lohman TG, Roche AF, Martorell R. Anthropometric standardization reference manual. Champaign: Human Kinetics Books; 1988.

28. IPAQ Research Committee. Guidelines for data processing and analysis of the International Physical Activity Questionnaire (IPAQ)-short and long forms. http://www.ipaqkise/scoring.pdf. 2005. Accessed 5 Jan 2020.

29. Longvah T, Anantan I, Bhaskarachary K, Venkaiah K. Indian food composition tables. National Institute of Nutrition, Indian Council of Medical Research; 2017.

30. Wickramanayake T. Food and nutrition. 3rd ed. Colombo: H. Kobbekaduwa Research Institute; 2002.

31. Furushima T, Miyachi M, lemitsu M, Murakami H, Kawano H, Gando Y, Kawakami R, Sanada K. Development of prediction equations for estimating appendicular skeletal muscle mass in Japanese men and women. J Physiol Anthropol. 2017;36:34

32. Xu W, Wang M, Jiang CM, Zhang YM. Anthropometric equation for estimation of appendicular skeletal muscle mass in Chinese adults. Asia Pac J Clin Nutr. 2011;20(4):551.

33. Lee MJ, Kim EH, Bae SJ, Choe J, Jung CH, Lee WJ, Kim HK. Protective role of skeletal muscle mass against progression from metabolically healthy to unhealthy phenotype. Clin Endocrinol. 2019;90(1):102-13.

34. Foong YC, Chherawala N, Aitken D, Scott D, Winzenberg T, Jones G. Accelerometer-determined physical activity, muscle mass, and leg strength in community-dwelling older adults. J Cachexia Sarcopenia Muscle. 2016;7(3):275-83.

35. Daly RM, Rosengren BE, Alwis G, Ahlborg HG, Sernbo I, Karlsson MK. Gender specific age-related changes in bone density, muscle strength and functional performance in the elderly: a-10 year prospective populationbased study. BMC Geriatr. 2013;13(1):71.

36. Santo Signorelli S, Neri S, Sciacchitano S, Di Pino L, Costa MP, Marchese G, Celotta G, Cassibba N, Pennisi G, Caschetto S. Behaviour of some indicators of oxidative stress in postmenopausal and fertile women. Maturitas. 2006;53:77-82.

37. Lord C, Chaput JP, Aubertin-Leheudre M, Labonte M, Dionne IJ. Dietary animal protein intake: association with muscle mass index in older women. J Nutr Health Aging. 2007;11(5):383.

38. Wolfe RR, Miller SL, Miller KB. Optimal protein intake in the elderly. Clin Nutr. 2008;27:675-84.

39. Bopp MJ, Houston DK, Lenchik L, Easter L, Kritchevsky SB, Nicklas BJ. Lean mass loss is associated with low protein intake during dietaryinduced weight loss in postmenopausal women. J Am Diet Assoc. 2008;108:1216-20.

40. Ceglia L. Vitamin D and skeletal muscle tissue and function. Mol Asp Med. 2008;29:407-14

41. Beliaeff S, Bouchard DR, Hautier C, Brochu M, Dionne IJ. Association between muscle mass and isometric muscle strength in well-functioning older men and women. J Aging Phys Act. 2008;16(4):484-93.
42. Woo J, Leung J, Sham A, Kwok T. Defining sarcopenia in terms of risk of physical limitations: a 5-year follow-up study of 3,153 Chinese Men and Women. J Am Geriatr Soc. 2009;57:2224-31.

43. Lee JS, Auyeung T-W, KwokT, Lau EM, Leung P-C, Woo J. Associated factors and health impact of sarcopenia in older Chinese men and women: a cross-sectional study. Gerontology. 2007:53:404-10.

44. da Câmara SM, Zunzunegui MV, Pirkle C, Moreira MA, Maciel ÁC. Menopausal status and physical performance in middle aged women: a cross-sectional community-based study in northeast Brazil. PLOS ONE. 2015;10:e0119480.

45. Jones TE, Stephenson KW, King JG, Knight KR, Marshall TL, Scott WB. Sarcopenia-mechanisms and treatments. J Geriatr Phys Therapy. 2009:32:39-45.

46. Morley J. Sarcopenia: diagnosis and treatment. J Nutr Health Aging 2008;12:452.

47. Mitchell WK, Atherton PJ, Williams J, Larvin M, Lund JN, Narici M. Sarcopenia, dynapenia, and the impact of advancing age on human skeletal muscle size and strength; a quantitative review. Front Physiol. 2012;3:260.

48. Taniguchi Y, Makizako H, Kiyama R, Tomioka K, Nakai Y, Kubozono T, Takenaka T, Ohishi M. The association between osteoporosis and grip strength and skeletal muscle mass in community-dwelling older women. Int J Environ Res Public Health. 2019;16:1228.

49. Bijlsma A, Meskers M, Molendijk M, Westendorp R, Sipilä S, Stenroth L, Sillanpää E, McPhee J, Jones D, Narici M. Diagnostic measures for sarcopenia and bone mineral density. Osteoporos Int. 2013;24:2681-91.

50. Lowndes J, Carpenter RL, Zoeller RF, Seip RL, Moyna NM, Price TB, Clarkson PM, Gordon PM, Pescatello LS, Visich PS. Association of age with muscle size and strength before and after short-term resistance training in young adults. J Strength Cond Res Natl Strength Cond Assoc. 2009;23:1915.

51. Damayanthi HD, Moy F-M, Abdullah KL, Dharmaratne SD. Handgrip strength and its associated factors among community-dwelling elderly in Sri Lanka: a cross-sectional study. Asian Nurs Res. 2018;12:231-6.

52. Mendes J, Afonso C, Moreira P, Padrão P, Santos A, Borges N, Negrão R, Amaral TF. Association of anthropometric and nutrition status indicators with hand grip strength and gait speed in older adults. J Parenter Enter Nutr. 2019;43:347-56.

53. Beavers KM, Beavers DP, Houston DK, Harris TB, Hue TF, Koster A, Newman $A B$, Simonsick EM, Studenski SA, Nicklas BJ. Associations between body composition and gait-speed decline: results from the Health, Aging, and Body Composition study. Am J Clin Nutr. 2013;97:552-60.

54. Lindsey C, Brownbill RA, Bohannon RA, Ilich JZ. Association of physical performance measures with bone mineral density in postmenopausal women. Arch Phys Med Rehabil. 2005;86:1102-7.

55. Kwon J, Suzuki T, Yoshida H, Kim H, Yoshida Y, Iwasa H, Sugiura M, Furuna T. Association between change in bone mineral density and decline in usual walking speed in elderly community-dwelling Japanese women during 2 years of follow-up. J Am Geriatr Soc. 2007;55(2):240-4.

\section{Publisher's Note}

Springer Nature remains neutral with regard to jurisdictional claims in published maps and institutional affiliations.

Ready to submit your research? Choose BMC and benefit from:

- fast, convenient online submission

- thorough peer review by experienced researchers in your field

- rapid publication on acceptance

- support for research data, including large and complex data types

- gold Open Access which fosters wider collaboration and increased citations

- maximum visibility for your research: over 100M website views per year

At BMC, research is always in progress.

Learn more biomedcentral.com/submissions 